\title{
On the key points of the construction of characteristic service area
}

\author{
Rongrong Qiang ${ }^{1 *}$, Zhiqiang Liu ${ }^{1}$, Xiaodong Shang ${ }^{1}$ and Tianwen Liang ${ }^{1}$ \\ ${ }^{1}$ Highway Research Institute of the Ministry of transport, Beijing, 100088, China
}

\begin{abstract}
Service area is an important part of expressway. The construction of characteristic thematic service area is of great significance for improving highway service facilities and ensuring highway traffic safety. Through the study of location, facility layout, landscape design and architectural design of the characteristic service area, this paper analyzes the key points of the construction of the characteristic service area, which is helpful for the design and construction of the open and multi-functional service area. On the basis of meeting the functional requirements of the service area, it is necessary to adapt measures to local conditions, create the service area landscape with distinct personality and outstanding characteristics, and show the regional culture.
\end{abstract}

\section{Introduction}

Service area is an important part of expressway. The construction of characteristic thematic service area is of great significance for improving highway service facilities and ensuring highway traffic safety. This paper analyzes the key points of the construction of characteristic service area through the research of location, facility layout, landscape design, architectural design, etc.

\section{Key points of construction of characteristic service area}

\subsection{Location of service area}

The location of service area should consider the protection, excavation and utilization of regional culture, which not only can not destroy the local natural landscape and cultural heritage, but also provide the best environment and space for architectural landscape design. In addition to the comprehensive consideration of terrain, features, geographical environment, distance and other factors, the choice of service area location should also focus on whether it is convenient to stimulate the local economy, especially for areas with relatively backward development and obvious dual industrial structure, so as to make the service area become the starter of local economic development. The location of special theme service area can be selected in the following areas.

2.1.1 Historical and cultural areas. Rich historical and cultural relics can bring vitality and vitality to the service area. In addition, the historical and cultural areas themselves are also tourist attractions, so their own traffic and people flow is large, which can make full use of the function of the service area. Beautiful natural landscape and surrounding places of interest can change the atmosphere of the journey and regulate people's mental state. Therefore, choosing scenic spots with beautiful scenery and places of interest as service areas can not only provide all-round services for tourist attractions, achieve the purpose of developing tourism economy and promoting regional economic development, but also provide pleasant natural conditions for tourists to meet their leisure and tourism needs The need for travel.

2.1.2 Location with superior natural geographical environment. Choosing the section with beautiful natural scenery to build service area can make drivers and passengers enjoy beautiful natural scenery and guide drivers to rest. The difference of the beautiful natural environment will show the uniqueness of the service area, arouse people's memory of the service area, so as to attract more people and cars to stay and promote the development of the service area.

2.1.3 Characteristic products rich areas. Use the service area to publicize and display local special products, and use the service area as a sales window to speed up the dissemination of local culture and the circulation of local special products. On the other hand, it is also conducive to the development of highway industrial economy, making the service area become a logistics distribution center, so as to create good economic benefits.

2.1.4 Select points that intersect with local roads or close to the city. Choosing the location of the service area at the intersection of the local road is conducive to the

$\overline{{ }^{*} \text { Corresponding author's e-mail: rr.qiang }} @$ rioh.cn 
local government, enterprises and the masses to take the service area as a springboard through the service area. On the one hand, it receives the radiation from the economically developed areas, on the other hand, it is also conducive to the development of the expressway industry economy, making the service area become the logistics distribution center, so as to create good economic benefits. First, it is conducive to the full utilization of resources such as supermarkets and restaurants in the service area; second, it is conducive to the rapid dissemination of local culture and the circulation of local special products; third, it is conducive to the export of local products and the acquisition of the best interests.

\subsection{Layout of internal facilities}

- The layout of service facilities shall be consistent with the activity rules of drivers and passengers, and shall follow the concept of "separation of passengers and vehicles, separation of passengers and freight".

- The design of through lane and on-site Lane shall fully consider the vehicle driving track and dynamic requirements.

- Pay attention to land saving and utilization, and arrange service area in combination with interchange and toll plaza.

- Adjust measures to local conditions, arrange flexibly, combine with natural terrain conditions, and integrate with surrounding landscape environment.

\subsection{Key points of landscape design}

2.3.1 In combination with the terrain, respect the ecological environment and make rational use of the land. Combining with the terrain and following the natural terrain, we must comply with the site selection, general layout, landscape environment and the design of single building. As for the landscape environment, it is also a means to reflect the characteristics of the service area by combining the terrain and respecting the ecological environment. When the landscape environment is arranged in the mountainous area, it should conform to the terrain to make the contour line of the slope more perfect; while in the place where the water source is abundant, the water source should be used to increase the affinity of the environment and make the environment more lively.

\subsubsection{Landscape environment and architecture are} integrated. When designing the service area, it is necessary to conduct in-depth and detailed research, observation and further speculation on the natural geographical environment and climate conditions around the service area, such as the natural geographical features, building orientation, climate conditions of the service area, and the relationship with the surrounding people's residence. Explore the plasticity of the service area, so that the architectural design, landscape design, internal space design of the service area are integrated with the terrain and landform of the surrounding area, and coordinate with each other, so that the design of the service area fully reflects the regional culture of the surrounding environment.

The landscape exists around the building. The service area should be coordinated with the surrounding environment to reduce the damage to the surrounding environment and the traces of human processing, rather than the abrupt existence. No matter in style, scale and plant selection, it should be combined with the service area to make the service area coordinated, coherent, unified and complete.

2.3.3 Integration of traditional culture. The traditional culture is cleverly expressed in the landscape, the cultural connotation of the service area is increased, and the surrounding landscape is continued to the service area, and the local flavor of the service area is strengthened, so that the local culture is conveyed, causing people's resonance.

2.3.4 Diversity of landscape environment design. Improve the diversity of service area landscape design. On the premise of meeting the ecological balance of the service area, through the arrangement of different species, flowers and plants, not only to increase the sense of hierarchy and rhythm of the service area, but also to meet the different visual requirements of people, and to increase the change of landscape. For example, in the landscape design, increase the agricultural leisure, agricultural experience and other landscapes that people can actually participate in, which can not only increase people's agricultural knowledge, but also improve the identifiability of the service area, well display the local culture, and improve the overall image of the service area.

\subsection{Key points of architectural design}

In the architectural design of the service area, the following aspects can be considered to creatively reflect the characteristics of the service area:

\subsubsection{Use of regional architectural symbols,} materials, etc. in the service area. Different regional environment and natural environment create different architectural forms and symbols, which are also the concentrated embodiment of local architectural culture and have uniqueness. Using the symbols, forms, colors and materials of local traditional buildings can not only increase the artistic characteristics of the service area, but also enhance the identifiability of the service area and attract more people and vehicles. For example, the architectural color of Yi People's houses is determined by the color of Yi People's traditional clothing. The local service area can adopt the red, black and yellow colors with Yi characteristics. 


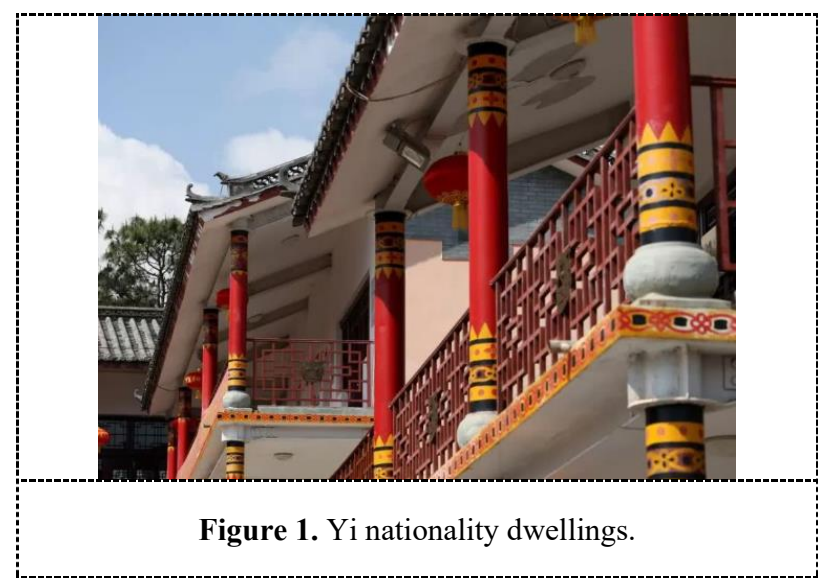

When selecting materials for buildings in service area, we should try to use local materials as much as possible, which can not only reduce the cost and save energy, but also coordinate the building with the local human and natural environment, making the building have unique regional characteristics and better reflect the essence of traditional architectural culture. For example, there are many stones in Dali, most of the Bai People's houses are made of local materials, and stones are widely used as the main building materials.

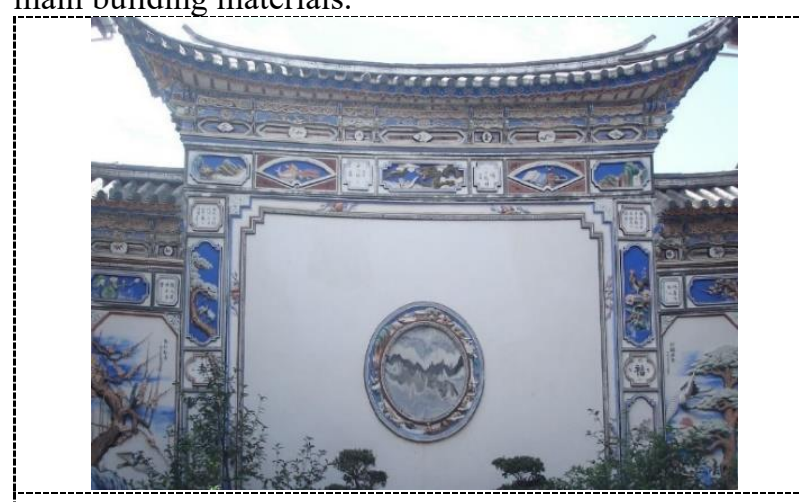

Figure 2. Dali Bai architecture.

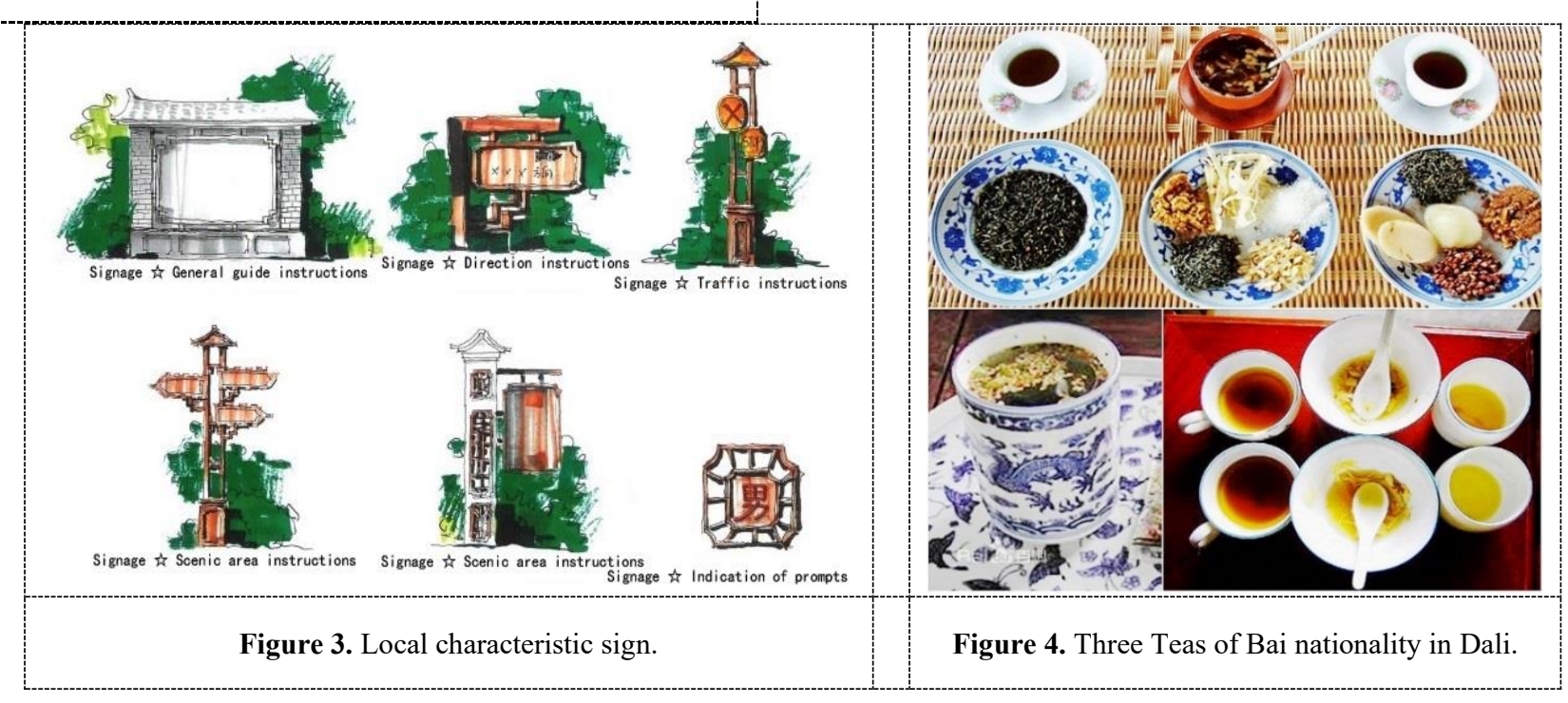

2.4.2 Display the history, culture, customs and customs in the service area. The design of the service area focuses on the local art works, living appliances, ancient cultural relics, various systems, academic achievements and other historical cultures. Grasp cultural life, human value, natural environment, customs, etiquette, habits and other local customs. On the basis of absorbing the essence of history and humanity, we carefully refine, generalize and boldly abstract the traditional culture. On the basis of inheritance, innovation makes the traditional culture sublimate in the design of service area.

2.4.3 Using new resources. Using new materials and reasonable functions to improve the identifiability of service area. New technologies are adopted to make the service area more able to meet the requirements of environmental protection and energy consumption reduction.

\subsubsection{Local characteristic buildings and products increase the characteristics of service area.} Environmental facilities are some facilities for people to use and serve in the outer space of the city, including kiosks, corridors, pavilions, sculptures, department stores, telephone booths, bulletin boards, signs, various lights, etc Using environment facilities and buildings to render regional culture and embellish the spatial environment of the service area can make the service area more distinctive.

The industrial and agricultural products and even characteristic plants displayed in the service area can increase the regional characteristics of the service area. The promotion of local regional products can also promote the rapid development of local economy and enhance the identifiability and regionality of service areas.

\subsection{Open service area design1}

The traditional expressway service area only provides rest and sorting functions for the drivers and passengers, vehicles and goods driving on the expressway. This closed operation mode blocks the natural contact of residents on 
both sides of the expressway, and also has shielding effect on the villages and towns along the expressway, which is not convenient for the travel of surrounding residents, nor for the material exchange in the surrounding areas. While the service area open to the outside world fully considers the needs of the surrounding residents, provides them with convenient travel conditions and perfect public service facilities, which not only reduces the no-load rate of Expressway vehicles, improves the transportation efficiency, but also solves the actual needs of residents along the line. In addition, due to its unique location advantages, it gathers a large number of people flow, logistics, capital flow, technology flow and information flow, which can effectively promote the economic prosperity and development of the surrounding areas of the service area.

\subsection{Multifunctional service area}

Break the single function form of service area, which only includes catering, rest, refueling, repair and other services, and establish a multi-functional service area. By increasing the construction of parks and scenic spots, developing agricultural planting, expanding holiday functions, mining intangible cultural heritage, increasing publicity functions and other measures, to meet the requirements of different groups for the service area, and make the service area present a diversified function and service trend To promote the development of the service area itself.

2.6.1 Develop leisure agriculture, increase the planting of plants and crops, and build leisure parks. Develop leisure agriculture characteristic service area, expand the planting area of plants and crops, build leisure park, develop rural fruit and vegetable garden and agritainment, etc., so that the service area can not only become a place for tourists to rest and eat, but also a place for leisure and entertainment, improve economic benefits, increase local income, and solve the problem of farmers' employment.

\subsubsection{Expand the function of vacation, increase the capacity of characteristic catering and residential reception. The expressway service area can not only expand leisure agriculture, develop the fruit tree picking Park of the plant viewing Park, but also develop the corresponding holiday supporting functions, increase service items, and increase the capacity of characteristic catering and residential reception.}

\subsubsection{Excavate intangible cultural heritage and} make full use of its economic value. The expressway service area can tap local cultural resources, including local traditional customs and festivals, traditional music, dance, quyi, traditional handicraft skills, etc. On the basis of fully protecting the local intangible cultural heritage, we should develop and utilize its economic and social value. Therefore, the expressway service area should give full play to its advantages of convenient transportation, provide a wide range of important marketing places for local cultural products produced in the process of protecting intangible cultural heritage, and at the same time achieve cultural, social and economic value.

\subsubsection{Increase the function of exhibition and publicity, and improve the popularity of local culture.} Expressway service area is an important window to display local features, reflect local culture and display local specialties. Therefore, in order to show its distinctive regional characteristics, it should not only meet the basic needs of vehicles and personnel in the past, but also increase the function of exhibition and sales promotion. It can not only fully display the regional culture, promote the tourist attractions, but also make good use of the commercial facilities in the service area, enrich and improve the exhibition contents and products, attract tourists from all directions, and promote local characteristic products.

\subsubsection{Increase special leisure tourism services. The} expressway service area can cooperate with the local tourism industry, use the window function to serve the local tourism industry and promote the development of the tertiary industry. As a node for passengers to rest and rectify, the service area can play a good role in its window function of external publicity, vigorously promote local characteristic tourism culture for tourism cities along the highway, and attract more tourists. In addition, the service area shall be equipped with corresponding facilities according to the actual situation. If there is a tourist attraction nearby, it can be considered to open a special tourist bus line in the service area to facilitate the tourists to quickly arrive at the tourist attraction. At the same time, the service area is equipped with tourism consultation, tourism information and scenic spot climate release platform, so that tourists can quickly grasp the information of the scenic spot to arrange their itinerary. Adding characteristic tourism services can also make the service area more characteristic.

\section{Conclusion}

The expressway service area is playing an increasingly important role in the transportation with its advantages of various points, and it has become the most commercial opportunity in the expressway economic industry. However, at present, most of the construction of expressway service areas has convergence and homogeneity, which restricts the further development of characteristic expressway service areas.

Based on the study of location selection, facility layout, landscape design, architectural design and construction of open and multi-functional service areas, this paper puts forward that on the basis of meeting the functional requirements of service areas, we should take measures according to local conditions, create a service area landscape with distinct personality and outstanding characteristics, show regional culture, and analyze the construction of service areas with Chinese characteristics. 


\section{References}

1. Ji W M., Dai H. (2015) Research on innovative design of expressway service area with regional characteristics. Highway transportation technology (Application Technology Edition)., 04: 212-213.

2. Gao J P., Xiao Y J., Lan B Z., Song R Q., Xia W. (2015) Functional positioning method of Expressway open service area. Journal of Chang'an University (Natural Science Edition)., 05: 44-48.

3. Huang B., He X., Yang Z C., Xu B H., Gao J P. (2014) Study on location and layout of expressway service area serving regional social and economic development. Highway., 04: 124-127.

4. Zhou L R. (2017) Research on the diversification strategy of service area planning and design. Art and Technology., 08: 314. 